\title{
Methimazole-induced insulin autoimmune syndrome in Graves' disease with hypokalemia: A case report and literature review
}

\author{
RONGFENG HAN and XIA JIANG \\ Department of Endocrinology, Tianjin First Center Hospital, Tianjin 300192, P.R. China
}

Received February 27, 2020; Accepted July 31, 2020

DOI: 10.3892/etm.2020.9221

\begin{abstract}
The patient in the present case report, a 27-year-old man, was diagnosed with Graves' disease and hypokalemia. The patient was treated with methimazole and intermittent potassium supplementation. Following treatment, the patient was still suffering from fatigue, accompanied by palpitations, a hand tremor, fear of heat and sweating. Hypoglycemia was revealed by monitoring fingertip blood glucose levels. The laboratory investigations indicated that serum insulin levels were significantly elevated $(>1,000 \mu \mathrm{IU} / \mathrm{ml})$, the test for serum insulin autoantibody (IAA) was positive, and insulin autoimmune syndrome (IAS) was diagnosed. Following symptomatic treatment, the patients insulin levels decreased, and the hypoglycemia episode was gradually relieved. Hypoglycemia may be prone to missed diagnosis in patients with Graves' disease and hypokalemic periodic paralysis. Monitoring fingertip blood glucose level is a convenient and feasible method to detect hypoglycemia. Furthermore, serum insulin and IAA detection should be assessed to exclude or confirm IAS.
\end{abstract}

\section{Introduction}

Insulin autoimmune syndrome (IAS) is a rare type of hypoglycemia, which was first reported in Japan by Hiram in 1970, which is why this disease is known as Hiram disease (1). Subsequently, IAS was also reported in China by Xiang et al (2). This disease is more common in individuals of Asian descent and less common in non-Asian populations (3). In Japan, IAS is the third leading cause of hypoglycemia, after insulinoma and extra pancreatic neoplasias (4). Hypoglycemia of IAS is characterized by spontaneous and irregular occurrence, and its severity can vary $(5,6)$. Although clinical manifestations are usually mild and transient, very severe cases have also been described, with prolonged hypoglycemia

Correspondence to: Dr Rongfeng Han, Department of Endocrinology, Tianjin First Center Hospital, 24 Fukang Road, Nankai, Tianjin 300192, P.R. China

E-mail: hanmenghappy@126.com

Key words: insulin autoimmune syndrome, hypoglycemia, hypokalemia, methimazole and life-threatening consequences (5). IAS is characterized by: i) Hyperinsulinemic hypoglycemia, ii) elevated insulin autoantibody (IAA) titers, iii) no prior exposure to exogenous insulin; and iv) no pathological abnormalities of the pancreatic islets (6). While the cause of IAS is not completely understood, previous exposure to environmental triggers such as medication and certain Human Leukocyte Antigen (HLA) types have been associated with the pathogenesis of this syndrome (5). IAS is a clinically rare disease, and is prone to misdiagnosis and missed diagnosis. The clinical data, diagnosis and treatment of IAS induced by methimazole in a patient with Graves' disease complicated with hypokalemia are described in the present case report.

\section{Case report}

The patient, who was male and 27-years-old, was referred to the People's Hospital of Jizhou District (Tianjin, China), due to palpitation, fatigue, fear of heat, sweating and weight loss of $10 \mathrm{~kg}$ within 3 months. The thyroid function test results are presented in Table I. The patient was diagnosed with hyperthyroidism and treated with methimazole (10 mg, 3 times daily). After 10 days of continuous methimazole administration, the patient had aggravated symptoms and developed paralysis of the limbs and labored breathing, with a blood potassium level of $1.91 \mathrm{mmol} / 1$ (normal range, 3.5-5.3 mmol/1). Following symptomatic treatment, which included intravenous and oral potassium supplementation, the patient improved, and was subsequently treated with intermittent potassium supplementation.

However, the patient still had intermittent fatigue and palpitations and was subsequently admitted to Tianjin First Center Hospital (Tianjin, China). The patients thyroid was diffusely enlarged on palpation and there was no exophthalmos. The cardiac and respiratory examination findings were unremarkable. The abdomen was soft and non-tender, without masses. The examination results of the thyroid function test performed following admission are also presented in Table I. The erythrocyte sedimentation rate was normal, while the thyroid color doppler ultrasound indicated that the thyroid gland double-lobe gland was enlarged, and blood flow was normal. The patient was diagnosed with Graves' disease and continued to be treated with methimazole $(10 \mathrm{mg}$, twice daily). Following treatment with potassium supplementation, the fluctuation in the blood potassium level was monitored 
Table I. Thyroid function test results.

A, The People's Hospital of Jizhou District, Tianjin

\begin{tabular}{lcc}
\hline Laboratory test & Test result & Reference range \\
\hline FT3, pmol/1 & $>30.8$ & $3.5-6.5$ \\
FT4, pmol/1 & 87.24 & $10.44-24.38$ \\
TSH $\mu$ IU/ml & 0.009 & $0.35-5.29$ \\
Anti-TPO, U/ml & $1,300.0$ & $\leq 60$ \\
Anti-TG, U/ml & 291.3 & $\leq 60$ \\
TRAb, IU/l & 9.11 & $0-1.75$ \\
\hline
\end{tabular}

\section{B, Tianjin First Center Hospital}

\begin{tabular}{lcc}
\hline Laboratory test & Test result & Reference range \\
\hline FT3, pmol/1 & 6.33 & $3.1-6.8$ \\
FT4, pmol/1 & 14.23 & $12.0-22.0$ \\
TSH $\mu \mathrm{IU} / \mathrm{ml}$ & 0.005 & $0.27-4.2$ \\
Anti-TPO, U/ml & 345.5 & $0-34$ \\
Anti-TG, U/ml & 287.9 & $0-115$ \\
TRAb, IU/l & 5.25 & $0-1.75$ \\
\hline
\end{tabular}

Anti-TG, anti-thyroglobulin; Anti-TPO, anti-thyroid peroxidase; FT3, free triiodothyronine; FT4, free thyroxine; TSH, thyroid stimulating hormone; TRAb, thyrotropin receptor antibody.

at 3.17-4.67 $\mathrm{mmol} / \mathrm{l}$ (normal range, 3.5-5.3 $\mathrm{mmol} / \mathrm{l}$ ); however, the symptoms, such as fatigue, palpitation and hand tremors, appeared intermittently. By monitoring the finger blood glucose level, it was demonstrated that the minimum finger blood glucose level was $1.90 \mathrm{mmol} / \mathrm{l}$, and the plasma blood glucose level was $2.44 \mathrm{mmol} / \mathrm{l}$. Therefore, a spontaneous hypoglycemia episode was identified. The patient had no history of diabetes mellitus or hypoglycemia and denied exposure to insulin or oral antidiabetic drugs. The glycosylated hemoglobin level was $6.0 \%$ (normal range, 4.0-6.0\%). The patient had an oral glucose tolerance test (OGTT), insulin release test and C-peptide release test (Fig. 1). The time intervals of these tests were $0,30,60,120$ and $180 \mathrm{~min}$. All results of the insulin release test were $>1,000 \mu \mathrm{IU} / \mathrm{ml}$. IAA was positive, while tests for glutamic acid decarboxylase antibody and islet cell antibody were negative. There were no abnormalities in routine blood, blood biochemistry, rheumatism immunity series, anti-nuclear antibody spectrum and adrenal function tests. A pancreatic CT and enhanced CT did not reveal any abnormalities. Using the Naranjo's assessment scale (7), the causal association had a score of 7 points (Table II). Considering hypoglycemia may be secondary to methimazole-induced IAS, methimazole was discontinued. The patient did not experience hypoglycemia again, once his eating habits were changed, he had more meals a day but with a reduction in the amount consumed. The patient was ingesting food higher in protein and fiber to delay gastric emptying and a slowdown in the insulin release rate. The examination before discharge indicated that the fasting serum insulin level $(634.0 \mu \mathrm{IU} / \mathrm{ml})$, was significantly

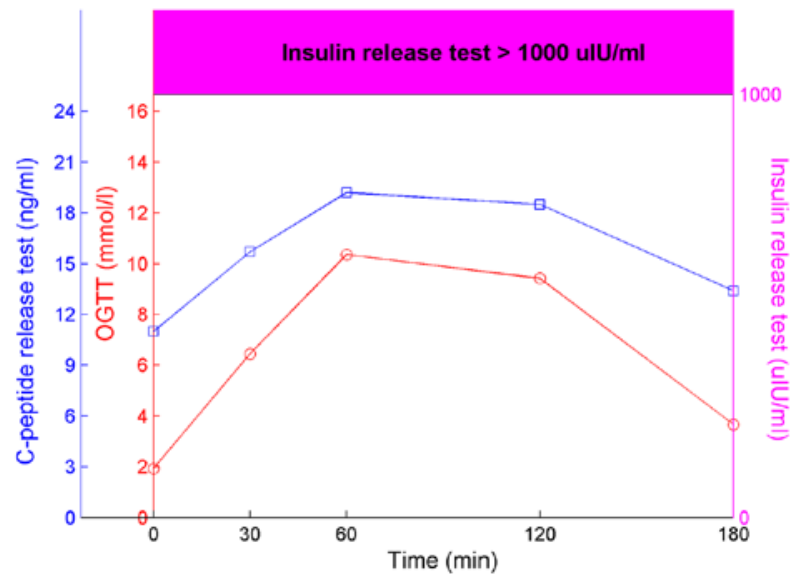

Figure 1. Results of oral glucose tolerance test, insulin and C-peptide release test on admission. OGTT, oral glucose tolerance test.

lower than before treatment. After 2 weeks, the patient was treated with I-131 $11 \mathrm{mCi}$. Outside of the hospital, using blood glucose monitoring, a hypoglycemia episode did not occur. Furthermore, the insulin level of the patient was lower, as presented in Fig. 2. The fasting blood glucose and insulin were recorded on days $0,9,17,31$ and 79 . The results of the OGTT, insulin and C-peptide tests are presented in Fig. 3 and were obtained $>2$ months after discharge. The time intervals of these tests were $0,30,60,120$ and $180 \mathrm{~min}$. The insulin and C-peptide levels had decreased markedly compared to those on admission, and no hypoglycemia occurred.

\section{Discussion}

The patient in the present case report presented with hypokalemia and hypoglycemia following treatment for hyperthyroidism with methimazole. Hypoglycemia may be easily missed at diagnosis or misdiagnosed (5). Following treatment with potassium supplementation, the patient experienced symptoms, such as fatigue, palpitation and hand tremors, which occurred intermittently. By monitoring finger blood glucose levels, spontaneous hypoglycemia episodes were identified. The patient had no history of diabetes mellitus and hypoglycemia, or exposure to insulin or oral antidiabetic agents. Therefore, hypoglycemia caused by oral hypoglycemic drugs or exogenous insulin was excluded. The insulin and C-peptide release test revealed that levels of insulin were elevated, and although the C-peptide level was high, it was not synchronized with the insulin level. IAA was indicated to be positive, and no pancreatic abnormalities were identified following a pancreatic CT. The patient discontinued with methimazole treatment. Using dietary management, hypoglycemia did not return. Therefore, hypoglycemia was indicated to be caused by IAS. IAS is a typical clinical symptom of recurrent, spontaneous and severe hypoglycemia induced by non-exogenous insulin in the blood and requires the identification of insulinoma. However, pancreatic space-occupying lesions are often observed in the CT images of patients with insulinoma, although some small insulinomas are difficult to locate. The elevated serum insulin level in these patients are synchronous with 
Table II. Naranjo's assessment scale.

\begin{tabular}{|c|c|c|c|c|c|}
\hline \multirow[b]{2}{*}{ Questions } & \multicolumn{3}{|c|}{ Score } & \multirow[b]{2}{*}{ Answer } & \multirow[b]{2}{*}{ Score } \\
\hline & Yes & No & Unknown & & \\
\hline $\begin{array}{l}\text { 1. Are there previous conclusive reports on this } \\
\text { reaction? }\end{array}$ & +1 & 0 & 0 & Yes & 1 \\
\hline 2. Did the adverse event appear after the suspected drug was administered? & +2 & -1 & 0 & Yes & 2 \\
\hline $\begin{array}{l}\text { 3. Did the adverse reaction improve when the drug was discontinued or a } \\
\text { specific antagonist was administered? }\end{array}$ & +1 & 0 & 0 & Yes & 1 \\
\hline 4. Did the adverse reaction reappear when the drug was readministered? & +2 & -1 & 0 & Unknown & 0 \\
\hline $\begin{array}{l}\text { 5. Are there alternative causes (other than the drug) that could on their } \\
\text { own have caused the reaction? }\end{array}$ & -1 & +2 & 0 & No & 2 \\
\hline 6. Did the reaction reappear when a placebo was given? & -1 & +1 & 0 & Unknown & 0 \\
\hline $\begin{array}{l}\text { 7. Was the drug detected in the blood (or other fluids) in concentrations } \\
\text { known to be toxic? }\end{array}$ & +1 & 0 & 0 & Unknown & 0 \\
\hline $\begin{array}{l}\text { 8. Was the reaction more severe when the dose was increased, or less } \\
\text { severe when the dose was decreased? }\end{array}$ & +1 & 0 & 0 & Unknown & 0 \\
\hline $\begin{array}{l}\text { 9. Did the patient have a similar reaction to the same or similar drugs } \\
\text { in any previous exposure? }\end{array}$ & +1 & 0 & 0 & No & 0 \\
\hline 10. Was the adverse event confirmed by any objective evidence? & +1 & 0 & 0 & Yes & 1 \\
\hline Total score & & & & & 7 \\
\hline
\end{tabular}

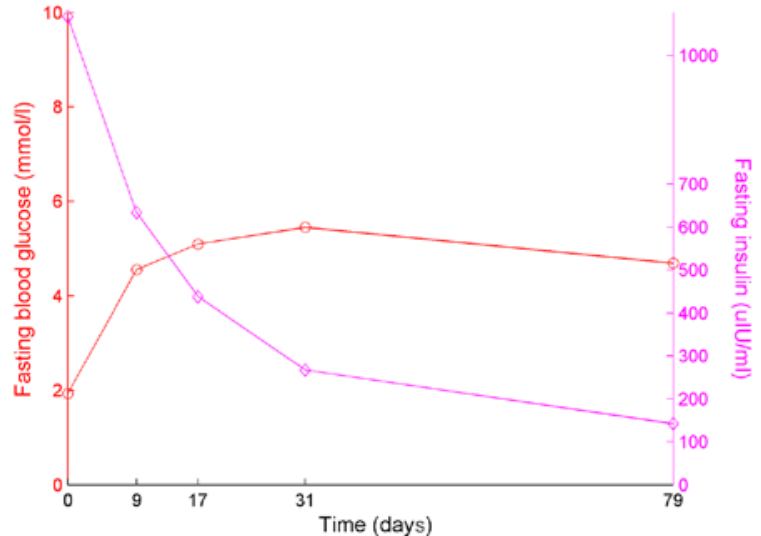

Figure 2. Results of monitoring fasting blood glucose and insulin.

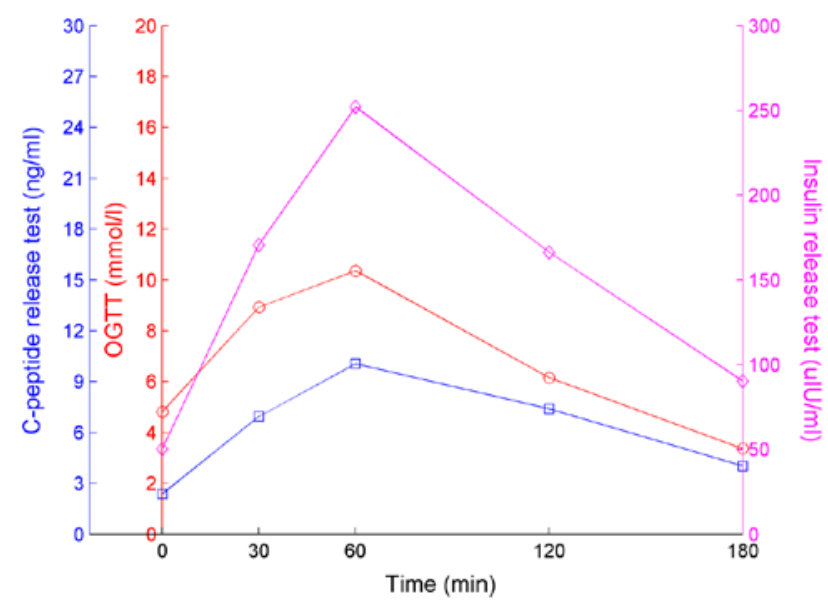

Figure 3. Results of oral glucose tolerance test, insulin and C-peptide release test $>2$ months following discharge. OGTT, oral glucose tolerance test.
C-peptide, and IAA is negative. The plasma C-peptide levels in patients with IAS have also been indicated to be elevated, but it is much lower compared with the insulin concentration in the blood, showing a state of separation of C-peptide from insulin (8). IAA has a high titer; therefore, detection of IAA, serum insulin and C-peptide levels can assist with identification of this disorder (9).

Using the Naranjo's assessment scale (7), the causal association had a score of 7 points (Table II), which supported the possible causal relationship between the use of methimazole and IAS. The pathogenesis of IAS is still unclear and it is currently hypothesized to develop from the combined action of autoimmune defects and IAA induced by the administration of specific drugs, on the basis of susceptibility genes $(4,6)$. Using sulfur/sulfhydryl-containing drugs is an important treatment method, and these include methimazole, captopril, D-penicillamine, hydralazine, glutathione, methionine, mercaptans, imipenem, penicillin $\mathrm{G}, \alpha$-lipoic acid and diltiazem (10). Any one of these can induce IAS, and methimazole is the most common treatment option (11). It has been debated that sulfur/sulfhydryl groups may be able to bind and reduce the sulfhydryl bonds connecting insulin chains $\mathrm{A}$ and $\mathrm{B}$, making endogenous insulin more immunogenic (12). Studies have demonstrated that IAA in patients with IAS is characterized by low affinity and high capacity $(4,13)$. IAA can also form an unstable complex with insulin, reduce the concentration of serum-free insulin, expand insulin storage capacity, and further stimulate islet $B$ cells to continue to secrete insulin. When the insulin-IAA complex dissociates, a large amount of free insulin is released into the blood to cause hyperinsulinemia, which in turn causes hypoglycemia (14). The patient in the present case report had a history of methimazole exposure, which 
Table III. IAS induced by methimazole from 2001 to September 2019 in China $(\mathrm{n}=64)$.

\section{Characteristic}

Number of cases

Sex

\section{Female}

Male

48

16

Age, years

$<60$

$\leq 60$
Hypoglycemia treatment

Diet adjustment

Diet adjustment + glucocorticoids

38

Diet adjustment $+\alpha$-glucosidase inhibitor

Diet adjustment + glucocorticoids +

$\alpha$-glucosidase inhibitor

Treatment of hyperthyroidism

I-131 therapy

PTU

First PTU and then I-131 therapy

4

Surgery

2

Discontinued methimazole without other

expressions

Blood glucose

$\geq 2.8$
$<2.8$

Hypokalemia

With

Without

HLA typing

With

Without the cases was indicated to be different, with 60 cases having blood glucose levels $>2.8 \mathrm{mmol} / 1$ and 4 cases with levels $>2.8 \mathrm{mmol} / \mathrm{l}$. The hypoglycemia episode patient described in the present case report was also irregular, and his lowest fingertip blood glucose level was $1.90 \mathrm{mmol} / \mathrm{l}$. A previous study (10) have indicated that the treatment of IAS first requires eliminating the inducement, discontinuing the causative drugs, dietary management, delaying gastric emptying by increasing the number of meals a day with a reduction in the amount and ingestion of high protein and high fiber food and slowing the release rate of insulin. $\alpha$-Glucosidase inhibitors have also been used to reduce or prevent hypoglycemic episodes $(4,13)$. In more severe or prolonged cases, glucocorticoids, immunosuppressants and plasmapheresis may be beneficial adjuvant therapies $(15,16)$. Of the 64 cases, 21 patients adjusted their diet, 38 patients were treated with combined glucocorticoid therapy, 2 patients were treated with combined $\alpha$-glucosidase inhibitors and 3 patients were treated with glucocorticosteroids and $\alpha$-glucosidase inhibitors to treat hypoglycemia. In the patient described in the present case report, there was no recurrence of hypoglycemia following diet management and the discontinuation of methimazole. When Graves' disease is combined with IAS, treatment with I-131 is often advocated (17). Of the 64 patients, 25 were treated with I-131, 19 were treated with propylthiouracil (PTU), 4 were switched to I-131 therapy following oral PTU treatment, 2 cases received surgical treatment and 14 cases were previously treated with methimazole only or it was not explicitly stated. Patients with hyperthyroidism receiving methimazole treatment may also develop IAS; however, not all the patients had Graves' disease. The patient in the present case report stopped methimazole treatment and was instead treated with radioactive iodine for Graves' disease. In previous studies $(18,19)$ it has been hypothesized that HLA-DR4 is a genetic susceptibility gene for IAS and is associated with the pathogenesis of IAS. In addition, studies have demonstrated that $84 \%$ of patients from Japan carry the HLA-DRB1*0406 allele (20), while European and American populations primarily carry the HLA-DRB1*0403 allele $(21,22)$. Unfortunately, the patient in the current case report did not undergo genetic testing. Of the 64 patients previously reported, 3 were genetically tested (23), and all the patients were indicated to carry the HLA-DRB1*0406 allele, which is consistent with the reported results of previous Asian populations.

The patient in the present case report exhibited IAS. The patient was also previously diagnosed with Graves' disease and suffered with intermittent hypokalemic periodic paralysis. Hypoglycemia might be easily missed in diagnosis or misdiagnosed. Monitoring fingertip blood glucose level is a convenient and feasible method to determine this. The majority of patients with IAS exhibit a good prognosis. However, it is a rare cause of hypoglycemia in clinical practice, and it is susceptible to misdiagnosis and missed diagnosis. This may lead to severe adverse effects, such as severe hypoglycemia and even disturbance of consciousness. For patients that also exhibit autoimmune diseases, who have used or are using suspicious drugs and are developing spontaneous hypoglycemia, insulin levels and IAA should be monitored in time. Therefore, early diagnosis and appropriate treatment should be conducted to

reduce adverse consequences for patients with IAS. early in the morning and as reactive hypoglycemia following the ingestion of food $(5,6)$. The degree of hypoglycemia in 


\section{Acknowledgements}

Not applicable.

\section{Funding}

No funding was received.

\section{Availability of data and materials}

The datasets used and/or analyzed during the present study are available from the corresponding author on reasonable request.

\section{Authors' contributions}

RH and XJ designed the study, collected and analyzed the clinical data, and wrote and revised the manuscript. Both authors read and approved the final manuscript.

\section{Ethics approval and consent to participate}

Ethical approval was granted by The Tianjin First Center Hospital (approval no. E2020011L).

\section{Patient consent for publication}

Informed consent was obtained from the patient, including for the publication of this report.

\section{Competing interests}

The authors declare that they have no competing interests.

\section{References}

1. Hirata $\mathrm{Y}$, Ishizu $\mathrm{H}$ and Ouchi $\mathrm{N}$ : Insulin autoimmunity in a case of spontaneous hypoglycemia. J Japan Diabetes Soc 13: 312-320, 1970.

2. Xiang D, Chen J, Xu M, Luo B, Wan C, Jin J, Fan H and Fu L: Insulin autoimmune syndrome report of a case and review of the literature. Chin J Endocrinol Metab 64: 94-97, 1985 (In Chinese)

3. Jendrzejewski J, Obołończyk Ł, Leczycka ME, Utracka A, Ciura P, Makowski W and Sworczak K: A case report of insulin autoimmune syndrome in a central european individual. Clin Chem Lab Med 56: e132-e134, 2018.

4. Savas-Erdeve S, Yilmaz Agladioglu S, Onder A, Peltek Kendirci HN, Bas VN, Sagsak E, Cetinkaya S and Aycan Z: An uncommon cause of hypoglycemia: Insulin autoimmune syndrome. Horm Res Paediatr 82: 278-282, 2014.

5. Ismail AA: Testing for insulin antibodies is mandatory in the differential diagnosis of hypoglycaemia in nondiabetic subjects. Clin Endocrinol 76: 603-604, 2012.

6. Censi S, Mian C and Betterle C: Insulin autoimmune syndrome: From diagnosis to clinical management. Ann Transl Med 6: 335 , 2018.

7. Naranjo CA, Busto U, Sellers EM, Sandor P, Ruiz I, Roberts EA, Janecek E, Domecq C and Greenblatt DJ: A method for estimating the probability of adverse drug reactions. Clin Pharmacol Ther 30: 239-245, 1981
8. Zheng C, Yang Y, Yang G, Ba J, Wang F, Dou J, Gu W, Guo Q, $\mathrm{Lv} \mathrm{Z}$ and $\mathrm{Mu} \mathrm{Y}$ : Insulin autoimmune syndrome: A report of 6 cases and literature review. Chin Gen Pract 15: 3313-3316, 2012 (In Chinese).

9. Okazaki-Sakai S, Yoshimoto S, Yagi K, Wakasugi T, Takeda Y and Yamagishi M: Insulin autoimmune syndrome caused by an adhesive skin patch containing loxoprofensodium. Intern Med 52: 2447-2451, 2013.

10. Reis MZR, Fernandes VO, Fontenele EGP, Sales APAM, Montenegro Junior RM and Quidute ARP: Insulin autoimmune syndrome in an occidental woman: A case report and literature review. Arch Endocrinol Metab 62: 566-570, 2018.

11. Hunter A, Graham U and Lindsay JR: Insulin autoimmune syndrome: A rare case of hypoglycaemia resolving with immunosuppression. Ulster Med J 87: 34-36, 2018.

12. Deguchi A, Okauchi Y, Suehara S and Mineo I: Insulin autoimmune syndrome in a health supplement user: The effectiveness of cornstarch therapy for treating hypoglycemia. Intern Med 52: 369-372, 2013

13. Nasu T, Suzuki R, Okamoto Y, Miyata K, Uno A, Nakao R, Kawashima A, Nakao T and Kondo M: Late postprandial hypoglycemia due to bioactive insulin dissociation from autoantibody leading to unconsciousness in a patient with insulin autoimmune syndrome. Intern Med 50: 339-343, 2011.

14. Zhang Y and Zhao T: Hypoglycemic coma due to insulin autoimmune syndrome induced by methimazole: A rare case report. Exp Ther Med 8: 1581-1584, 2014.

15. Saxon DR, McDermott MT and Michels AW: Novel management of insulin autoimmune syndrome with rituximab and continuous glucose monitoring. J Clin Endocrinol Metab 101: 1931-1934, 2016.

16. Chu JP, Zheng XW, Lu J, Zhong JY, Li JL, Xu M and Lin F: Insulininduced autoimmune syndrome: Acase report. Exp Ther Med 12: 3359-3362, 2016

17. Xu T: Analysis of 71 cases of insulin autoimmune syndrome. Chin J Immunol 32: 1053-1055, 2016 (In Chinese).

18. Uchigata Y, Eguchi Y, Takayama-Hasumi S, Omon Y, Hirata Y, Kuwata S, Tokunaga K, Miyamoto M and Juji T: Strong association of insulin autoimmune syndrome with HLA-DR4. Lancet 339: 393-394, 1992.

19. Matsushita S, Takahashi K, Motoki M, Komoriya K, Ikagawa S and Nishimura Y: Allele specificity of structural requirement for peptides bound to HLA-DRB1*0405 and-DRB1*0406 complexes: Implication for the HLA-associated susceptibility to Methimazole-induced insulin autoimmune syndrome. J Exp Med 180: 873-883, 1994.

20. Uchigata $Y$ and Hirata $Y$ : Insulin autoimmune syndrome (IAS, Hirata disease). Ann Med Interne (Paris) 150: 245-253, 1999.

21. Censi S, Albergoni MP, Gallo N, Plebani M, Boscaro M and Betterle C: Insulin autoimmune syndrome (Hirata's Disease) in an Italian patient: A case report and review of the literature. Clin Chem Lab Med 56: 889-895, 2018.

22. Uchigata Y, Hirata Y, Omori Y, Iwamoto Y and Tokunaga K: Worldwide differences in the incidence of insulin autoimmune syndrome (Hirata disease) with respect to the evolution of HLA-DR 4 alleles. Hum Immunol 61: 154-157, 2000.

23. Chen $\mathrm{C}$, Wang $\mathrm{W}$, Jin J, Ni W, Gu T, Bi Y and Zhu D: Methimazole-induced insulin autoimmune syndrome in Graves' disease: A case report and review on literature. J Clin Pathol Res 39: 904-908, 2019 (In Chinese).

This work is licensed under a Creative Commons Attribution-NonCommercial-NoDerivatives 4.0 International (CC BY-NC-ND 4.0) License. 